\title{
Antimicrobial Activity of Phenolic Compounds Extracted from Platanus hybrida: Exploring Alternative Therapies for a Post-Antibiotic Era ${ }^{+}$
}

\author{
Jessica Ribeiro 1, Vanessa Silva 1,2,3,4, Alfredo Aires 5, Rosa Carvalho 6, Gilberto Igrejas 2,3,4 and \\ Patrícia Poeta ${ }^{1,4 *}$ \\ 1 Microbiology and Antibiotic Resistance Team (MicroART), Department of Veterinary Sciences, University \\ of Trás-os-Montes and Alto Douro (UTAD), Vila Real, Portugal; jessicalribeiro@gmail.com; \\ vanessasilva@utad.pt \\ 2 Department of Genetics and Biotechnology, University of Trás-os-Montes and Alto Douro, Vila Real, \\ Portugal; gigrejas@utad.pt \\ 3 Functional Genomics and Proteomics Unit, University of Trás-os-Montes and Alto Douro (UTAD), Vila Real, \\ Portugal; \\ 4 Associated Laboratory for Green Chemistry (LAQV-REQUIMTE), University NOVA of Lisbon, Caparica, \\ Portugal; \\ 5 Centre for the Research and Technology of Agro-Environmental and Biological Sciences (CITAB), University \\ of Trás-os-Montes and Alto Douro (UTAD), Vila Real, Portugal; alfredoa@utad.pt \\ 6 Department of Agronomy, School of Agrarian and Veterinary Sciences, University of Trás-os-Montes e Alto \\ Douro (UTAD), Vila Real, Portugal; rpaula@utad.eu \\ * Correspondence: ppoeta@utad.pt; Tel.: +351-259350466; Fax: +351-259350629 \\ + Presented at the $1^{\text {st }}$ International Electronic Conference on Microbiology, 02-30 November 2020; Available \\ online: https://ecm2020.sciforum.net/
}

Received: Accepted: Published:

\begin{abstract}
Multidrug-resistant bacteria are a significant threat to public health and new classes of antibiotics and approaches to treatment are needed. Several studies showed that natural plantderived compounds could be a promising mean to fight microbial resistance but only a few were conducted with antibiotic resistant bacteria. Therefore, the aim of this study was to extract phenolic compounds from the leaves, fruits and tree trunk of Platanus hybrida and evaluate their antimicrobial activity against antibiotic resistant bacterial strains. The polyphenolic compounds were extracted using a water/ethanol (20:80) mixture. Two grams of powder of each sample was extracted with 100 $\mathrm{mL}$ of solvent by stirring for $2 \mathrm{~h}$. The extracts were redissolved in dimethyl sulfoxide (DMSO) to a final concentration of $100 \mathrm{mg} / \mathrm{mL}$. Antimicrobial susceptibility assay was performed using KirbyBauer disc diffusion method and was tested against ten different bacteria: Listeria monocytes, Bacillus cereus, Enterococcus faecium, Enterococcus faecalis, Staphylococcus aureus, Staphylococcus epidermidis, Salmonella enteritidis, Pseudomonas aeruginosa, Klebsiella pneumoniae and Escherichia coli. The fruits had the highest antibacterial activity showing a minimum inhibitory concentration (MIC) of $10 \mathrm{mg} / \mathrm{mL}$, contrary to the tree trunk that showed the lowest antibacterial activity. None of the extracts showed antimicrobial properties against $S$. enteritidis, E. faecium and E. faecalis. These results show that, $P$. hybrida's phenolic compounds act as antibacterial agents which may become useful therapeutic tools and represent a source for the development of novel antimicrobials. However, they were not effective against all bacteria which shows that polyphenols, alone, might not substitute antibiotics.
\end{abstract}

Keywords: polyphenols; plant-derived compounds; plane tree; antimicrobial activity; bacterial resistance; public health. 


\section{Introduction}

Antibiotics are substances with the capacity to selectively inhibit or kill microorganisms [1]. Their discovery was one of the greatest scientific breakthroughs of the $20^{\text {th }}$ century and they became routinely used not only in human medicine but also in livestock production as therapeutic agents or growth promoters [2]. Misuse of antibiotics has resulted in the emergence of resistant bacteria against at least one antibiotic, which is generating a problem affecting public health. Bacteria have a remarkable capacity to adapt to adverse environmental conditions which allows them to remain active even when in contact with antimicrobial substances [1,3]. Many researches have shown a growing number of infections caused by resistant bacteria in hospitals and communities [4]. Bacterial resistance has accompanied the development and commercialization of antibiotics. At the beginning of the antibiotic era, concern was focused on resistance in Gram-positive bacteria. However, in recent decades, attention has shifted to the susceptibility pattern of Gram-negative bacteria [5]. Among the Gram-positives, Staphylococcus aureus stands out for causing infections ranging from simple skin diseases to severe conditions such as bacteremia and endocarditis. Escherichia coli has resistance to several drugs, such as carbapenemases, cephalosporins, among others. Pseudomonas aeruginosa are Gram-negative bacteria with high virulence. These are only some examples of bacteria that act as opportunistic microorganisms that can cause severe infections and even sepsis [6]. According to data obtained by the World Health Organization (WHO), the ability of bacteria to resist to the available antibiotics causes about 700 thousand death per year and it is estimated that this number will increase considerably, reaching 10 million deaths per year by 2050. Besides this, antimicrobial resistance will have economic implications: studies show that the world may lose between 60 and 100 trillion dollars in economic production, which represents a decrease of 2.0 to $3.5 \%$ of global gross domestic product (GDP) expected for 2050 [3]. This scenario has led to the development of research aimed at identifying new antimicrobial agents through chemical synthesis or isolation from natural products [6].

Plants have been used from many centuries for therapeutic purposes. It is an ancient practice that has been empirically transmitted from generation to generation [6,7]. The WHO estimates that $80 \%$ of the population of some Asian and African countries presently uses medicinal plants to treat many diseases. Several scientific studies realized in the USA and Europe have revealed that their use is increasing in recent years which proves their important therapeutic effect [7]. The therapeutic properties of medicinal plants have been attributed to the presence of secondary metabolites which plays a critical physiological role in these organisms but also interferes with pharmacological targets in humans and many other species [4]. A large number of plants have been screened as a source of natural antioxidants including tocopherols, vitamin $\mathrm{C}$, carotenoids and phenolic compounds which helps the human body to reduce oxidative damage and provide protection against heart disease, cancer and Alzheimer. Furthermore, it was already demonstrated that several plant-derived polyphenolic compounds exhibited important antimicrobial, antioxidant, anticancer and apoptosisinducing properties [7]. Platanus hybrida Brot. (syn. Platanus $x$ acerifolia (Ait.) Willd, Platanus $x$ hispanica Mill. Ex Münchh), also known as London Plane, is a hybrid between Platanus occidentalis L. (American origin) and Platanus orientalis L. (Oriental origin) $[8,9]$. This specie belongs to Platanaceae family and it was first reported in Europa in the 17th century [10]. These trees usually flower from March to April and fruit in late summer and autumn [8]. Since its appearance, $P$. hybrida has been valued highly as an ornamental tree providing shade and as a source of wood for different uses [9,10]. As a result, it is a very popular street tree in Europe and elsewhere of the world. In addition, it is widely used as an urban tree because it provides a large number of ecosystem services, grows fast, has a good tolerance to urban microclimate conditions and it is quite resistant to soil compaction and air pollution. The London Plane tree's pollution tolerance is due to its ability to accumulate pollutants in its cortex and most importantly because of its high capacity to capture Particule Matter (PM) due to the morphological characteristics of its leaves [9]. This way, considering the current need to search for alternative sources of antimicrobial compounds or compounds with antibiotic resistance-modulatory effects, in this work, we extracted the phenolic compounds of the leaves, fruits and trunk of this plane tree and investigated their antimicrobial activity against a wide range of multidrug-resistant bacteria. 


\section{Materials and Methods}

\subsection{Plant Material and Extract Preparation}

Plant material used included three plane tree components, namely, the trunk, fruits and leaves. Samples were collected in July 2020 in the North of Portugal. These components were manually separated, lyophilized, mill-powdered, and stored at $-20{ }^{\circ} \mathrm{C}$. The polyphenolic compounds were extracted using a water/ethanol (20:80) mixture. Two grams of powder of each powdered sample was extracted with $100 \mathrm{~mL}$ of solvent by stirring for $2 \mathrm{~h}$. Samples were centrifuged for $15 \mathrm{~min}$ at 10,000 RPM. The supernatants of each extraction were collected, filtered, and the solvent evaporated on a rotary evaporator at $40{ }^{\circ} \mathrm{C}$ under reduced pressure. Finally, the obtained dry residues were weighted and redissolved in dimethyl sulfoxide (DMSO) to a final concentration of $100 \mathrm{mg} / \mathrm{mL}$ for the analysis of antimicrobial activity. The extracts were stored under $-20{ }^{\circ} \mathrm{C}$ until further analysis.

\subsection{Antibacterial Activity}

\subsubsection{Bacterial Strains}

Antimicrobial susceptibility testing was performed against six multidrug-resistant Grampositive bacteria (Listeria monocytes, Bacillus cereus, Enterococcus faecium, Enterococcus faecalis, Staphylococcus aureus and Staphylococcus epidermidis) and four multidrug resistant Gram-negative bacteria (Pseudomonas aeruginosa, Klebsiella pneumoniae, Salmonella enteritidis e Escherichia coli). The strains are part of the University of Trás-os-Montes and Alto Douro and University of La Rioja collections. All the bacterial strains were subcultured from the original culture in brain heart infusion (BHI) agar (Oxoid, Basingstoke, UK) for $24 \mathrm{~h}$ at $37^{\circ} \mathrm{C}$. Muiller-Hinton (MH) agar (Oxoid, Basingstoke, UK) was used for the antimicrobial susceptibility assay.

\subsubsection{Antimicrobial Susceptibility Test}

The antimicrobial susceptibility assay was performed using the Kirby-Bauer disc diffusion method. Each bacterial strain was seeded in BHI agar plates and incubated overnight at $37{ }^{\circ} \mathrm{C}$. Colonies were suspended in physiological solution to a turbidity equivalent to 0.5 McFarland standard and inoculated on $\mathrm{MH}$ plates. The initial extract solution of $100 \mathrm{mg} / \mathrm{mL}$ was diluted with DMSO to $75,50,25$, and $10 \mathrm{mg} / \mathrm{mL}$ and tested against the ten multidrug-resistant bacteria for the evaluation of antimicrobial susceptibility. Twenty microliters of each extract concentration were loaded on sterile blank discs ( $6 \mathrm{~mm}$ diameter) and the discs were placed on the inoculated MH plates, which were incubated for $24 \mathrm{~h}$ at $37^{\circ} \mathrm{C}$. The inhibition zones were measured with a ruler, recorded, and considered as indication for antibacterial activity.

\section{Results and Discussion}

The assessment of antimicrobial activity by $P$. hydrida's components was performed using the Kirby-Bauer disc diffusion method. The results for the minimum inhibitory concentration (MIC) are expressed in Table 1. All extracts showed antimicrobial activity with clear-cut inhibition zone and, as expected, different extracts exhibit different antimicrobial effects. Nevertheless, it is important to notice that, unlike most studies, we used antibiotic resistant bacteria which have several mechanisms that confers them resistance to antibiotics and several natural compounds.

L. monocytogenes was the only bacteria that showed susceptibility to all the extracts. Ceruso et al. (2020), explored the potential antibacterial activity of an extraordinary vast collection of plant extracts against this pathogen and demonstrated similar results [11]. It has often been reported that polyphenolic extracts are more efficient against Gram-positive bacteria [12]. Cell walls of Gramnegative represent a major barrier for the entry of phenolic compounds into cell cytoplasm due to the repulsion between lipopolysaccharide found in the surfaces of Gram-negative bacteria and phenols [13]. However, in this study, phenolic extracts did not have any effect against two Gram-positive bacteria (E. faecium and E. faecalis) and one Gram-negative bacteria (S. enteritidis). The susceptibility 
results against $S$. enteritidis are in line with the obtained in other studies made with polyphenols extracted from winery by-products [14]. The resistance of phenolic compounds action by multidrugresistant bacteria is not completely understood but the same results of antimicrobial activity of $E$. faecalis and E. faecium could be explained by the fact that they share, not only the genus Enterococcus, but also similar antibiotic resistances and resistance genes [15].

Tabel 1. Minimum inhibitory concentration (MIC, $\mathrm{mg} / \mathrm{mL})$ and inhibition zones $(\mathrm{mm})$ of the phenolic extracts from the trunk, fruits and leaves against multidrug-resistant Gram-positive and Gram-negative bacteria.

\begin{tabular}{cccc}
\cline { 2 - 4 } Bacterial Strain & \multicolumn{2}{c}{ MIC $(\mathbf{m g} / \mathbf{m L})($ Inhibition zones $(\mathbf{m m}))$} \\
\cline { 2 - 4 } Gram-positive & $100(10)$ & Fruit & Leaf \\
L. monocytogenes & - & $10(9)$ & $10(8)$ \\
B. cereus & - & $25(11)$ & - \\
S. aureus & - & $25(8)$ & $50(9)$ \\
S. epidermidis & - & $25(10)$ & $25(13)$ \\
E. faecalis & - & - & - \\
E. faecium & - & - & $75(9)$ \\
Gram-negative & - & $25(12)$ & $10(10)$ \\
P. aeruginosa & - & $10(12)$ & $25(10)$ \\
K. pneumoniae & - & $10(9)$ & - \\
E. coli & - & - & - \\
S. enteritidis & & & \\
\hline
\end{tabular}

The higher susceptibility zone $(19 \mathrm{~mm})$, which was caused by the fruit extracts, was observed against E. coli. In general, fruit extracts had the better antimicrobial efficacy, since they had effect against eight of the ten bacteria tested and showed lower MIC values. In a study conducted by Chatzigeorgiou et al. (2017), the chemical composition of Platanus orientalis is characterized by the presence of fatty acids, terpenoids, coumarins and especially flavonoids and flavonoid glycosides. It was also reported that natural products isolated from the fruits of $P$. orientalis exert antioxidant effects, active proteostatic mechanisms and delay human cells senescence which could explain the high efficiency of the fruit extracts against the bacteria used in our study [16]. Contrarily, the trunk extracts only had effect against L. monocytogenes with MIC of $100 \mathrm{mg} / \mathrm{mL}$. The phenolic compounds can express their microbicide effect through different mode of action. These molecules can suppress several microbial virulence factors (e.g., by inhibition of biofilm formation, reduction of host ligand adhesion and neutralization of bacterial toxins), reduce the fluidity of membrane, inhibit the synthesis of nucleic acids and the cell wall or energy metabolism. In addition, the different phenolic compounds may have synergetic effect between them. The presence and number of hydroxyl groups in phenolic compounds is responsible for their antioxidant properties. Changes in the position of this group could play an important role in the antimicrobial activity and the interactions with cell membrane structures [17]. The leaves extracts showed antimicrobial efficacy against six bacteria. Several studies revealed that Platanus species leaves contain flavonoids, pentacyclic triterpenoids, tannins and caffeic acid and they have many pharmacological activities such as cytotoxic, cytostatic, antimicrobial and antiseptic effects [15].

Overall, the polyphenols extracted from P. hydrida exhibited a good antibacterial activity against several pathogenic bacteria resistant to antibiotics, presenting better results when compared, with those reported for other Platanus species trees, such as P. orientalis [16]. 


\section{Conclusions}

The sensitivity of multidrug-resistant bacteria to natural phenolic compounds depends on bacterial species, the purity and the polyphenol structure of the phenolics as well as the methods used for the experiments. We are aware that more studies, including in vivo experiments, should be undertaken to better clarify the molecular mechanisms underlying the protection of plane tree extracts against pathogenic bacteria. Nevertheless, the obtained results add evidence that these extracts can be an interesting source of phenolic compounds with antimicrobial activities which may provide assistance to antibiotics. Furthermore, the utilization of phenolic compounds extracted from plane tree has significant importance within the circular economy principles of production and utilization of natural resources. However, in order to widely apply phenolic compounds as antimicrobials coadjutor, their safety and toxicity must be further investigated.

Author Contributions: conceptualization, J.R and V.S.; methodology, J.R., V.S., A.A. and R.C.; validation, A.A., G.I. and P.P..; investigation, J.R. and V.S..; writing-original draft preparation, J.R.; supervision, G.I. and P.P.

Funding: Please add: "This research received no external funding" or "This research was funded by NAME OF FUNDER, grant number XXX" and "The APC was funded by XXX". Check carefully that the details given are accurate and use the standard spelling of funding agency names at https://search.crossref.org/funding, any errors may affect your future funding.

Acknowledgments: This work was also supported by the Associate Laboratory for Green Chemistry-LAQV which is financed by national funds from FCT/MCTES (UID/QUI/50006/2020). Vanessa Silva is grateful to FCT (Fundação para a Ciência e a Tecnologia) for financial support through PhD grant SFRH/BD/137947/2018.

Conflicts of Interest: The authors declare no conflict of interest.

\section{References}

1. Imane, N.I.; Fouzia, H.; Azzahra, L.F.; Ahmed, E.; Ismail, G.; Idrissa, D.; Mohamed, K.H.; Sirine, F.; L'Houcine, O.; Noureddine, B. Chemical composition, antibacterial and antioxidant activities of some essential oils against multidrug resistant bacteria. Eur. J. Integr. Med. 2020, 35, 101074, doi:10.1016/j.eujim.2020.101074.

2. Ben Said, L.; Emond-Rheault, J.G.; Soltani, S.; Telhig, S.; Zirah, S.; Rebuffat, S.; Diarra, M.S.; Goodridge, L.; Levesque, R.C.; Fliss, I. Phenomic and genomic approaches to studying the inhibition of multiresistant Salmonella enterica by microcin J25. Environ. Microbiol. 2020, 22, 2907-2920, doi:10.1111/1462-2920.15045.

3. de Oliveira, M.S.; Oshiro-Junior, J.A.; Sato, M.R.; Conceição, M.M.; Medeiros, A.C.D. Polymeric nanoparticle associated with ceftriaxone and extract of schinopsis brasiliensis engler against Multiresistant enterobacteria. Pharmaceutics 2020, 12, 1-18, doi:10.3390/pharmaceutics12080695.

4. de Araújo, A.C.J.; Freitas, P.R.; Barbosa, C.R.D.S.; Muniz, D.F.; Rocha, J.E.; de Araújo Neto, J.B.; da Silva, M.M.C.; Moura, T.F.; Pereira, R.L.S.; Ribeiro-Filho, J.; et al. Essential oil of croton ceanothifolius Baill. Potentiates the effect of antibiotics against multiresistant bacteria. Antibiotics 2020, 9, 1-8, doi:10.3390/antibiotics9010027.

5. Perdigão Neto, L.V.; Oliveira, M.S.; Orsi, T.D.; Prado, G.V.B. do; Martins, R.C.R.; Leite, G.C.; Marchi, A.P.; Lira, E.S. de; Côrtes, M.F.; Espinoza, E.P.S.; et al. Alternative drugs against multiresistant Gram-negative bacteria. J. Glob. Antimicrob. Resist. 2020, 23, 33-37, doi:https://doi.org/10.1016/j.jgar.2020.07.025.

6. Freitas, P.R.; de Araújo, A.C.J.; dos Santos Barbosa, C.R.; Muniz, D.F.; Rocha, J.E.; de Araújo Neto, J.B.; da Silva, M.M.C.; Silva Pereira, R.L.; da Silva, L.E.; do Amaral, W.; et al. Characterization and antibacterial activity of the essential oil obtained from the leaves of Baccharis coridifolia DC against multiresistant strains. Microb. Pathog. 2020, 145, 104223, doi:10.1016/j.micpath.2020.104223.

7. Edziri, H.; Haddad, O.; Saidana, D.; Chouchen, S.; Skhiri, F.; Mastouri, M.; Flamini, G. Ruscus hypophyllum L. extracts: chemical composition, antioxidant, anticoagulant, and antimicrobial activity against a wide range of sensitive and multi-resistant bacteria. Environ. Sci. Pollut. Res. 2020, 27, 17063-17071, doi:10.1007/s11356-020-08159-8.

8. Alcázar, P.; Galán, C.; Torres, C.; Domínguez-Vilches, E. Detection of airborne allergen (Pla a 1) in relation to Platanus pollen in Córdoba, South Spain. Ann. Agric. Environ. Med. 2015, 22, 96-101, doi:10.5604/12321966.1141376. 
9. Cariñanos, P.; Ruiz-Peñuela, S.; Valle, A.M.; de la Guardia, C.D. Assessing pollination disservices of urban street-trees: The case of London-plane tree (Platanus x hispanica Mill. ex Münchh). Sci. Total Environ. 2020, 737, 139722, doi:10.1016/j.scitotenv.2020.139722.

10. Pilotti, M.; Brunetti, A.; Tizzani, L.; Marani, O. Platanus $\times$ acerifolia genotypes surviving to inoculation with Ceratocystis platani (the agent of canker stain): First screening and molecular characterization. Euphytica 2009, 169, 1-17, doi:10.1007/s10681-009-9884-9.

11. Ceruso, M.; Clement, J.A.; Todd, M.J.; Zhang, F.; Huang, Z.; Anastasio, A.; Pepe, T.; Liu, Y. The inhibitory effect of plant extracts on growth of the foodborne pathogen, listeria monocytogenes. Antibiotics 2020, 9, 113, doi:10.3390/antibiotics9060319.

12. Silva, V.; Igrejas, G.; Falco, V.; Santos, T.P.; Torres, C.; Oliveira, A.M.P.; Pereira, J.E.; Amaral, J.S.; Poeta, P. Chemical composition, antioxidant and antimicrobial activity of phenolic compounds extracted from wine industry by-products. Food Control 2018, 92, 516-522, doi:10.1016/j.foodcont.2018.05.031.

13. Silva, V.; Singh, R.K.; Gomes, N.; Soares, B.G.; Silva, A.; Falco, V.; Capita, R.; Alonso-Calleja, C.; Pereira, J.E.; Amaral, J.S.; et al. Comparative insight upon chitosan solution and chitosan nanoparticles application on the phenolic content, antioxidant and antimicrobial activities of individual grape components of Sousão variety. Antioxidants 2020, 9, doi:10.3390/antiox9020178.

14. Silva, V.; Igrejas, G.; Falco, V.; Santos, T.P.; Torres, C.; Oliveira, A.M.P.; Pereira, J.E.; Amaral, J.S.; Poeta, P. Chemical composition, antioxidant and antimicrobial activity of phenolic compounds extracted from wine industry by-products. Food Control 2018, 92, 516-522, doi:10.1016/j.foodcont.2018.05.031.

15. Kutbay, I.; Akfırat, F.Ş. Mapping of Biochemical Constituents in Platanus acerifolia Leaves By Analytical Techniques. Procedia - Soc. Behav. Sci. 2015, 195, 1719-1727, doi:10.1016/j.sbspro.2015.06.287.

16. Chatzigeorgiou, S.; Thai, Q.D.; Tchoumtchoua, J.; Tallas, K.; Tsakiri, E.N.; Papassideri, I.; Halabalaki, M.; Skaltsounis, A.-L.; Trougakos, I.P. Isolation of natural products with anti-ageing activity from the fruits of Platanus orientalis. Phytomedicine 2017, 33, 53-61, doi:https://doi.org/10.1016/j.phymed.2017.07.009.

17. Takó, M.; Kerekes, E.B.; Zambrano, C.; Kotogán, A.; Papp, T.; Krisch, J.; Vágvölgyi, C. Plant phenolics and phenolic-enriched extracts as antimicrobial agents against food-contaminating microorganisms. Antioxidants 2020, 9, doi:10.3390/antiox9020165.

(C) 2019 by the authors; licensee MDPI, Basel, Switzerland. This article is an open access article distributed under the terms and conditions of the Creative Commons Attribution (CC-BY) license (http://creativecommons.org/licenses/by/4.0/). 